\title{
On the Advantages of Specific Airway Resistance*
}

\author{
I. DAB ${ }^{(26)}$ AND F. ALEXANDER \\ Respiratory Physiology Department of the Astmacentrum, De Haan aan Zee, and Department of Pediatrics of the Free \\ University of Brussels (V.U.B.), Brussels, Belgium
}

\begin{abstract}
Summary
The specific airway resistance $\left(\mathrm{SR}_{\mathrm{aw}}\right)$ is a relatively precise parameter of bronchial quality and in normal children its relation with body length, although very significant $(P<0.001)$, is so poor that it can safely be disregarded (Fig. 4). Also the dispersion around the mean value remains stable at any body size (Fig. 4). Contrasting with the inverse relation between airway resistance $\left(R_{a w}\right)$ and lung volume, $S R_{a w}$ does not show any systematic variation with lung filling (Fig. 5). These data are consistent with the new formulas: $\mathrm{SR}_{\mathrm{aw}}=\operatorname{tg} \beta\left(\mathrm{P}_{\mathrm{B}}-\mathrm{P}_{\mathrm{H}_{2} \mathrm{O}}\right)$ and $\mathbf{R}_{\mathrm{aw}}=\mathrm{SR}_{\mathrm{aw}} /$

* This study was supported by Grant 3.0015.75, National Fund for Medical and Scientific Research in Belgium. It was made possible by the consent of the parents and the kind collaboration of the children as well as both the authorizations of the Minister of National Education and the director of the school.
\end{abstract}

TGV in which $\operatorname{tg} \beta$ stands for the relation between the plethysmographic box volume and breathing flow fluctuations (Fig. 2); $P_{B}$ - $\mathbf{P}_{\mathrm{H}_{2} \mathrm{O}}$ represents the ambient pressure corrected for water vapor pressure at body temperature; TGV is the thoracic gas volume at mean expiratory level. In disease $\mathbf{S R}_{\mathrm{aw}}$ varies more rapidly and markedly with any alteration of the airways than does $\mathbf{R}_{\mathrm{aw}}$ (Fig. 6). Consequently, a normal value for $S R_{\text {aw }}$ would indicate that both $R_{a w}$ and TGV must be in a normal range.

\section{Speculation}

For those who operate with a whole body plethysmograph the authors purpose to use specific airway resistance more frequently for the study of lung mechanics in children. It is a reliable parameter which can be measured very quickly and this should enhance knowledge about the mechanism of many lung diseases in pediatrics. 
In a previous paper it has been shown that SRow can be established and calculated quickly without knowing either the Row or the IGV at which Row is measured (4). There would be no benefit to this finding if the knowledge of Row consequently it becomes important to judge the clinical value of SRaw in comparison with Row and TGV in many situations, especially since in small children SRaw will be often the only obtainable plethysmographic measurement (4).

\section{MATERIAL AND METHODS}

\section{SUBJECTS}

Two hundred and fo rty two non selected schoolchildren (23), i.e. all those for whom the parent's consent was acquired ( $70 \%$ of the total schoolpopulation) served to calculate mean values and dispersions for SRaw. TGV and Row. Most of the children were studied on two occasions to test individual the height from 94.5 to $182 \mathrm{~cm}$.

Thirty six of the normal children and seventeen as thmatic patients from an Thirty six of the normal children and seventeen as thmatic patients from an
institution for respiratory disordered children (As tmacentrum - Zeepreventorium, De Haan) regularly undergoing lung function testing, were specially trained to breathe at different levels during the measurements (fig. 1). Fifteen of the latter performed also a histamine provocation test with a metered aerosol ( $\mathrm{His}$ tamine acid phosphate 100 micrograms in each puff, Riker Laboratories, Loughborough, England). The number of puffs was gradually increased until a percept ble variation occured in the $\beta$ angle (fig. 2) which represented SRaw and then SRaw. TGV and Raw were determined.

\section{METHODS}

$A_{R}$ pressure compensated volume displacement whole body plethysmograph (Pulmorex (24)) was used, equipped inside with a Douglas bag of about 60 liters and was connected to a heated Fleisch pneumotachograph no. 3 which was $i$ tself conwas connected to a heated Fleisch pneumotachograph no. 3 which was itself con-
nected on the other side to a mouth piece to measure breathing flows $(\Delta V)$ at BTPS conditions. The integration of these flows served to record respiratory volumes. The integration of the flow signal of a second but unheated fleisch volume variations ( $\left.\Delta V_{\theta}\right)$.

The calculations of SRew, TGV and Raw were fully described earlier (4). The formulas used will be recapitulated here :

\begin{tabular}{|c|c|c|}
\hline 1. & SRaw & $=\operatorname{tg} \beta\left(\mathrm{PE}_{1,}-\mathrm{P}_{\mathrm{H}_{2} \mathrm{O}} \mathrm{O}\right)$ \\
\hline 2 & TGV & $=\operatorname{tg} a\left(P_{B}, r-P_{H_{2}} \mathrm{O}\right)$ \\
\hline 3. & Rew & $=S_{\text {Rew }} / \mathrm{TGV}$ \\
\hline
\end{tabular}

3.

Raw $=$ SRew / TGV

Equation 3 was obtained from the usual definition of SRaw $=$ TGV $\times$ Row .

\section{RESULTS}

The relation between SRow and body length is very poor $(r=0.13$, fig. 4) but nevertheless very significant as it is the result of a study in a large population $(p<0.001)$. The slope however is only 0.03 , consequently we can safely disregard the increase of SRaw with body size for normal children between 3 and 16 years of age and consider the mean value as constant. This confirms previ-
ous findings (6). The difference between the mean value of the first determious findings $(6)$. The difference between the mean value of the first determinations and that of the second determinations is less than $0.02 \mathrm{CmM}_{2} \mathrm{O} . \mathrm{sec}$ and
is statistically not significant $(p>0.92)$. The comparison of the differences is $s$ tatistically not significant ( $p>0.92)$ The comparison of the differences
between the first and second determination in each child separately shows an between the first and second determination in each child separately shows an average intraindividual variation of only $13 \%$. As a result SRew can be regarded as a relatively precise parameter. is dispersion around the mean seent to be a biologic characteristic since it is stable for any height and is distributed according to statistical laws (fig. 4) (19). Simplifying we will con-
sider the mean value for SRaw to be $10 \mathrm{~cm}+\mathrm{s}$. Sec and the $95 \%$ upper prediction sider the mean value for $S R_{e w}$ to be $10 \mathrm{~cm} \mathrm{Ho.} \mathrm{Sec} \mathrm{and} \mathrm{the} 95 \%$ upper prediction
limit as $16 \mathrm{~cm} \mathrm{H} \mathrm{H}_{2} \mathrm{O}$.sec. The reason for the heigher values in this study as oplimit as $16 \mathrm{~cm} \mathrm{H}_{2} \mathrm{O}$. $\mathrm{sec}$. The reason

TGV could not be measured for ail the children because the Pflueger maneuver (breathing movements against a closed shutter in the mouth piece) was sometimes impossible. We obtained a TGV of 465 times with the 242 children.
data we were able to calculate the predicted mean regression curve :

$$
\text { TGV }=90.5958 \times 1.0202^{\text {Height }}
$$

However, for small children the observed values were far more scattered than for the taller ones (table 1). The reason for this is chiefly a poorly performed Pflueger maneuver by the very small children as has been extensively discussed earlier (4).

There is no significant difference between the first and second determinations $(p>0.15)$ but the intraindividual variations average $18 \%$. Whenever TGV could be measured, it was possible to calculate Raw (equation 3 ).
The formula for the predicted mean regression curve is :

$$
72.9146 \times 0.9832^{\text {Height }}
$$

A statistically significant though relatively poor negative exponential correlation is found between Raw and the height of the subjects $(r=-0.69)$. There is no significant difference between the first and second determina-
tions, but the intraindividual variations also average $18 \%$ which is clearly tions, but the intraindividual variations also average $18 \%$ which is clearly more important than for SRow. The diminished precision is only due to the
difficulty with which TGV is obtained and thus concerns principally small children (table 1).

Starting from formula 1, SRaw should not depend on the lung volume. The experiment on 34 normal and 17 as thmatic children who were asked to breathe at different lung volume levels (fig. 1) demonstrates this. In this experiment both SRow and Row were simultaneously measured; Raw varied inversely with the both SRow and Row were simultaneously measured ; Raw varied inversely with the

ung filling (fig. 5A), and SRew showed no sys tematic variation (fig. 5B). lator inhalation (fig. 6) are more important than the simultaneously measured Row deviations $(p<0.001)$.

\section{DISCUSSION AND CONCLUSION}

The tools used and the working methods applied by different authors can vary in many ways and therefore it is hard to overcome all possible difficuities in tandardizing methods for the evaluation of normal values. This accounts for the large variations of the normal values obtained by different investigators
$(5,9,10,18)$. For want of uniformi ty each inquirer should elaborate and fix
his own standards which al though they are not accurate should nevertheless be his own standards which al though they are not accurate should neverthe less be
precise $(20)$. In our study the mean value for SRew is larger than the means precise $(20)$. In our $s$ tudy the mean value for SRow is larger than the means
reported by others $(2,6,12,16)$. This can be explained primarily by the nor- mal breathing rate at BTPS conditions with our non selected children. Clement et al. (3) demonstrated that during panting, a common technique to simulate BTPS conditions (7), the glottis opening is markedly wider than at low flow rates, thereby causing large variations in the airway resistance $(8,11,14)$. In the second place the $\Delta V_{B} / \Delta \dot{V}$ curves are $S$-shaped because resistive forces increase with flow. This sinuosity in the curves inevitably causes ambiguities in the determination of the slope and the $\beta$ angle $(1,13,15,17,21,22)$. In our opinion the use of fixed inspiratory and expiratory flow points, for in-
stance $0.5 \mathrm{y}$ /sec. is not applicable in pediatrics. Indeed some smail children will never reach this flow with tidal breathing; other children will have their peak flows near $0.5 \mathrm{l} / \mathrm{sec}$. and the tallest will have the $0.5 \mathrm{l} / \mathrm{sec}$. point on the linear part of the curve (fig. 2). Confronted with this situation we decided to aiways join the extreme inspiratory and expiratory flow points and we expected that in this manner the curves of all the subjects at any age or any helght could be analyzed in the same conditions. Further we have observed bronchial obstruction than the change of the linear part of the slope. Though this method could be criticized, we have found it very convenient as shown by the satisfactory reproducibility of our

calculation method is also arbitrary.

Our investigation corroborated that $S R_{a w}$ is almost constant in a normal population after the age of 3 years (fig. 4) whatever the size of the subject or the volume of the lung (fig. 5B). This is consistent with the basic formula 1. On the other hand in disease, SRew varies more rapidly and more markedly with any alteration of the airways than does Row (fig. 6). We interpret this result in terms of formula 3 , which indicates that in a measurement of Raw. hyperinflation of the lungs reduces the effect of obstruction of the airways. Minor bronchial obstruction can escape notice by disregarding SRow. This can occur when the increase of either Row or TaV is insufficienty which can be measured with a body plethysmograph and which needs very little cooperation of the patients.

SRow alone does not yield separate information on lung size and resistive forces that oppose air displacement. Therefore the single use of SRow in the appreciation of lung mechanics in oider children will only result in saving some time, hence there is no other reason not to make the separate measurements of Rew and TGV also. On the contrary in small children, it will of ten be the only reliable and sometimes the only available measurement obtained with a considerable dispersion of the normal values and the poor individual reproducibility (4) make them useless for clinical application. However resulting from the greater sensitivity of SRaw, a normal value would indicate that both Raw and IGV must be in a normal range, where
that at least one of them is abnormal.

\section{REFERENCES}

1. Bouhuys, A. : Breathing. Physiology, environment and iung disease. Grune \& Stratton, New York-London, 160 (1974)

2. Briscoe, W.A., and Dubois, A.B. : The relationship between airway resistance, airway conductance and lung volume in

3. Clement, J., Stanescu. D.C., and van de Woestijne, K.P. : Glottis opening and effort-dependant part

4. Dab, and Alexander, $F$. : A simplified approach in the measurement of the specific ainway resistance. Pediat. Res. 10 : 996 (1976).

5. Doershuk, C.F., Downs, T.D., Matthews, L.W., and Lough, M.D. : A me thod for ventilatory measurements in subjects 1 month -5 years of age : norm
results and observations in disease. Pediat. Res. $4: 165$ (1970).

6. Doershuk, C.F., Fisher, B.J., and Matthews, L.W. : Specific airway resistance from perinatal period into adul thood. Am. Rev. Resp.Dis. 109 : 452 (1974).

7. Du Bois, A.B., Botelho, S.Y., and Comroe Jr., J.H. : A new method for measuring airway resistance in man using a body plethysmograph. J.Clin. Invest. $35: 327$ (1956). 8. Ferris Jr., B.G., Mead, J., and Opie, L.H. : Partitioning of respiratory
flow resistance in man. J.Appl. Physiol. $19: 653$ (1964).

9. Geubelle, F. : Volumes pulmonaires, capacités ventilatoires chez l'enfant. Presses Universitaires Liège (1973).

10. Haiuszka, J. : Application of the whole body plethysmography in examination of respiratory system in children and youth. National Institute for Teutsch M.A.). Rabka, 93-126 (1976).

11. Hyatt, R.E., and Wilcox, R.E. : Extrathoracic ainway resistance in man. J. Appi.Physiol. $16: 326$ (1961).

12. Lloyd Jr., T.C., and Wright, G.W. : Evaluation of methods used in detecting changes of airway resistance in man. Amer. Rev. Resp.Dis. $87: 529$ (1963).

13. Marshal, R., and Dubois, A.B. : The measurement of viscous resi

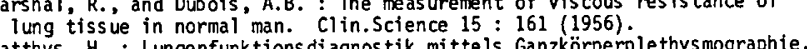

14. Matthys, $H$. : Lungenfunktions diagnostik mittels Ganzkörperple F.K. Schattauer Verlag, Stuttgart-New York, $22-25$ (1972).
Nolte, D., Reif, E., and Ulmer, W.T. : Die Ganzkörperplethysmographie. Respiration $25:$ : 14 (1968).
Role

16. Payne Jr., C.B., Chester, E.H., and Hsi, B.P. : Airway responsiveness in chronic obstructive pulmonary disease. Amer.J.Med. 42 : 554 (1965). Peset, R., Quanjer, P.H., and Tammeling, G.J. : Bronchodilation estimated by body plethysmography (comparison between the panting and spontaneous breathing methods). "Body Plethysmography" Progr
search, S. Karger, Basel-New York, 216 (1969).

18. Poigar, G., and Promadhat, $V$. : Pulmonary function testing in children. Techniques and standards. W.B. Saunders Company, Philadelphia-London-ToTechniques and 5 tandards.
ronto, $121,173(1971)$. 19. Sokal, R.R., and Rohlf, F.J. : Biometry. The principles and practice of
statistics in biologic research. W.H. Freeman and Company, San Francisco, $166(1919)$.

20. Ibid. chapter 2, p. 13 : Accuracy and precision of data. und Pathophysiologie, Methodik. Georg thieme, Stuttgart, 136 (1966).

22. Woitowitz, H.J., Buchheim, F.W., and Woitowitz, R. : Zur Theorie und Praxis der Ganzkörperplethysmographie in der Lungenfunktionsanalyse. Praxis der der Ganzkörperple thys mograph
Pneumologie $21: 449$ (1967).

23. Rijksmiddelbareschool, Klemskerke, Belgium.

24. Fenyves and Gut : Medizinischer Elektronik, Basel, Switserland.

24. Fenyves and Gut : Medizinischer Elektronik, Basel, Switserland.
25. The writers thank M.F. Vinaimont for his carefull assistance with the respiratory function tests, and Mrs. Vanmassenhove for the repeated and
pirater piratory function tests, and Mrs.
thorough typing of the manuscript.

26. Requests for reprints should be addressed to: I. Dab, M.D., Universitair Ziekenhuis St. Pieter, Dienst Kindergeneeskunde, Hoogstraat, 320, 1000 Brussels (Belgium)

27. Received for publication February 10, 1977 
Table 3. Estimation of the precision of TGV and Raw with respect to body size

\begin{tabular}{|c|c|c|c|c|}
\hline $\begin{array}{l}\text { Height } \\
(\mathrm{cm})\end{array}$ & $\begin{array}{c}\text { Mean TGV } \\
\text { (milliliters) }\end{array}$ & $\begin{array}{c}\text { Coef. Var. }{ }^{\mathrm{Xx}} \\
(\%)\end{array}$ & $\begin{array}{c}\text { Mean Raw } X \\
\left(\mathrm{~cm} \mathrm{H} \mathrm{H}_{2} \mathrm{O} / 1 / \mathrm{sec}\right)\end{array}$ & $\begin{array}{c}\text { Coef.Var. }{ }^{\mathrm{Xx}} \\
(\%)\end{array}$ \\
\hline $\begin{array}{r}95 \\
105 \\
115 \\
125 \\
135 \\
145 \\
155 \\
165 \\
175 \\
185\end{array}$ & $\begin{array}{r}606 \pm 175 \\
740 \pm 323 \\
903 \pm 223 \\
1104 \pm 295 \\
1348 \pm 205 \\
1646 \pm 310 \\
2015 \pm 332 \\
2455 \pm 367 \\
3000 \pm 425 \\
3663 \pm 416\end{array}$ & $\begin{array}{l}29 \\
44 \\
25 \\
27 \\
15 \\
19 \\
17 \\
15 \\
14 \\
11\end{array}$ & $\begin{array}{r}14.58 \pm 4.6 \\
12.31 \pm 4.2 \\
10.39 \pm 4.0 \\
8.77 \pm 3.7 \\
7.40 \pm 2.2 \\
6.25 \pm 2.0 \\
5.28 \pm 1.6 \\
4.45 \pm 1.1 \\
3.76 \pm 0.90 \\
3.17 \pm 0.62\end{array}$ & $\begin{array}{l}32 \\
34 \\
38 \\
42 \\
30 \\
32 \\
30 \\
25 \\
24 \\
20\end{array}$ \\
\hline
\end{tabular}

$x$ Values represent mean and 1 SD.

$x \times$ Coefficient of variation (SD/mean $\times 100$ ).

The individual values are grouped in classes of $10 \mathrm{~cm}$. The mean values for each class mark is calculated from this sample and is aiways very close to the value calculated from the exponential regression equation. The SD of each class mark is calculated from the dispersion of the individual values around the mean value of that class mark.

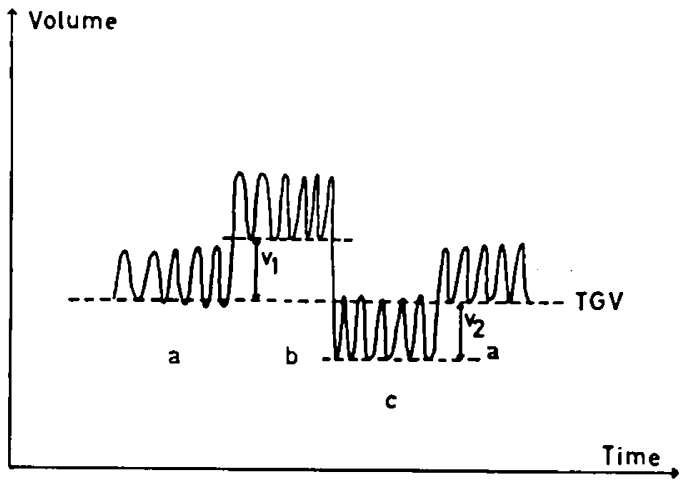

Fig. 1. Normal breathing (a) at spontaneous expiratory level (TGV); breathing at higher (b) i.e. TGV $+V_{3}$, and at lower (c) i.e. TGV $-V_{2}$ expiratory lev els. Lung volume is determined at any level ( $P f$ ) through a Pflueger maneuver (breathing movements against a closed shutter in the mouth peace). The volume

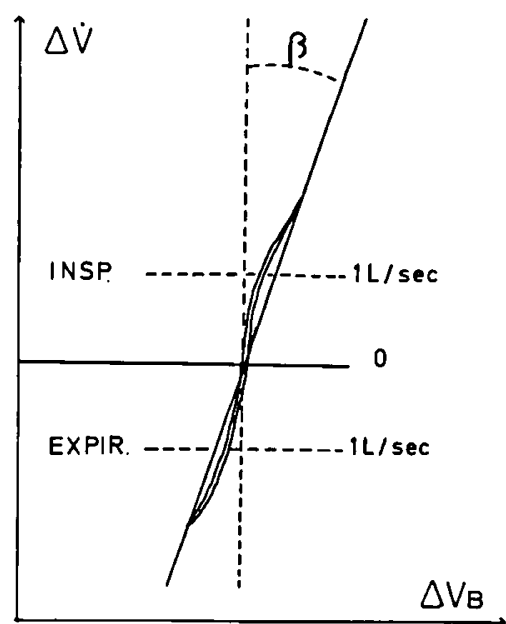

Fig. 2. Measurement of SRaw with a whole body plethysmograph. The relation between plethysmographic box volume variations $\left(\Delta V_{\theta}\right)$ and respiratory flow fluctuations $(\Delta V)$ during breathing at BTPS conditions.

$\Delta V_{B} / \Delta V=\operatorname{tg} \beta$

$S R_{\text {aw }}=\operatorname{tg} \beta\left(P_{\text {ear }}-P_{\mathrm{H}_{2}} \mathrm{O}\right)$

(4).
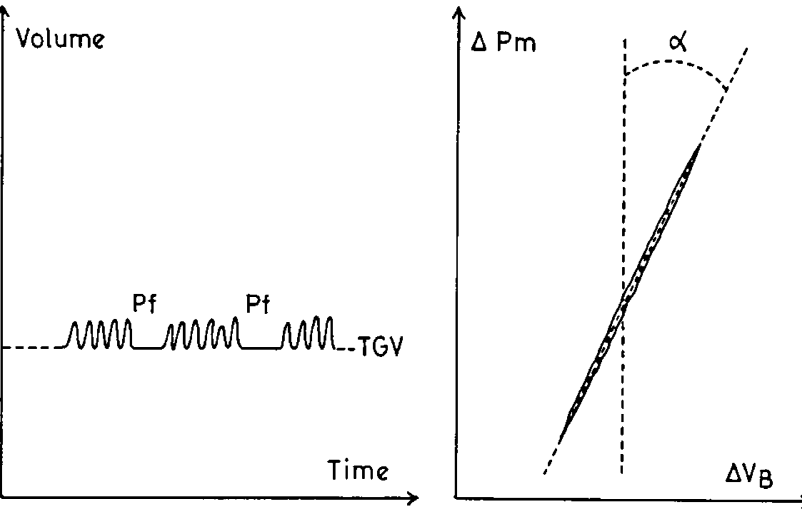

Fig. 3. Measurement of TGV with a whole body plethysmograph.

A. Normal breathing is interrupted (Pf) at the end of some expirations by a shutter in the mouth piece.

$B$. Recording of the breathing movements against the closed shutter or Pflueger maneuver. The lung volume (V) can be against the closed shutter or pfluegthe box volum the box volume variations ( $\left.\Delta V_{B}\right)$ and the static mouth pressure variations

$(\Delta \mathrm{Pm})$.e.

$\Delta V_{B} / \Delta P_{m}=\operatorname{tg} a \quad V=\operatorname{tg} a\left(P_{B a r}-P_{H_{2} O} O\right)$

If the shutter is closed exactly at the mean end expiratory level, $V$ represents the sum of TGV and the volume of the mouth piece.

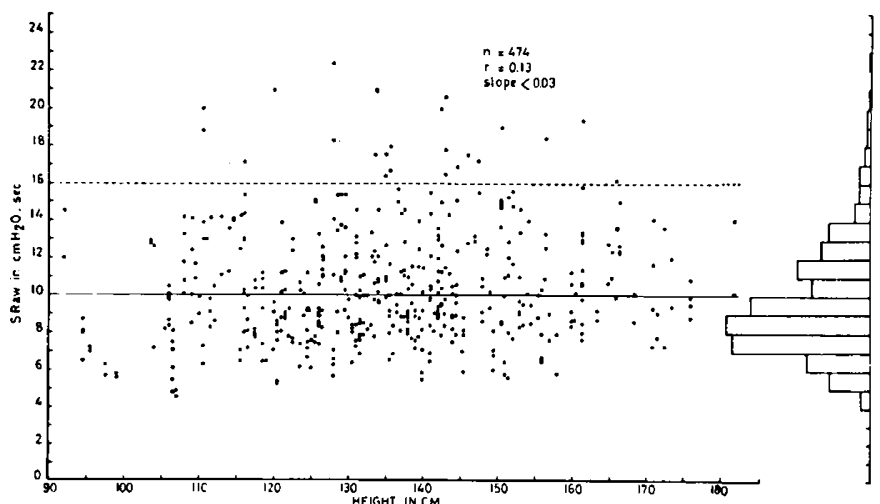

Fig. 4. SRow is poorly related to body length. The geometric mean is preferred since the frequency distribution is skewed (diagram at the right of the More import (19). For all the measurements together this mean is $10.10 \mathrm{Cm} \mathrm{H}_{2} \mathrm{O} . \mathrm{Sec}$ ror test (19) which is $16 \mathrm{~cm} \mathrm{H}_{2} \mathrm{O}$. Sec.
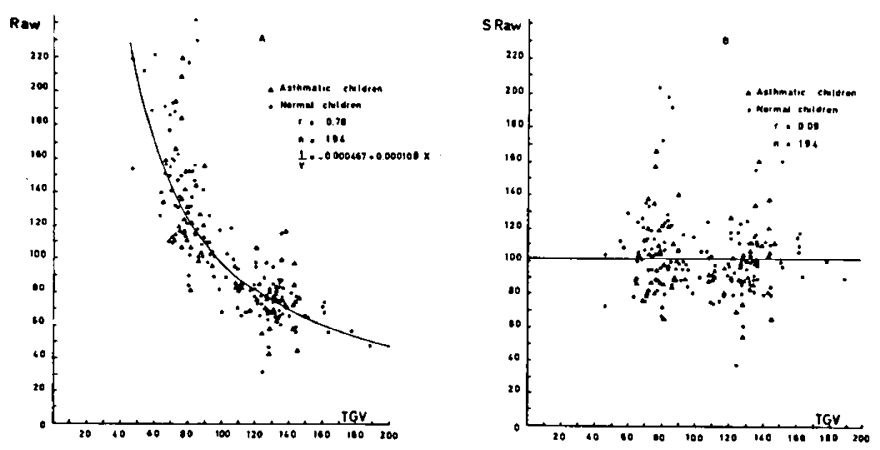

Fig. 5. Relative change of Row (A) and SRaw (B) in normal and as thmatic children with respect to the relative variations of the lung volume as shown in. figure 1 . The values at the end expiratory level during normal breathing are indicated in terms of $100 \%$

Raw and TGV are inversely related as shown by the hyperbolic regression of the observed data. 


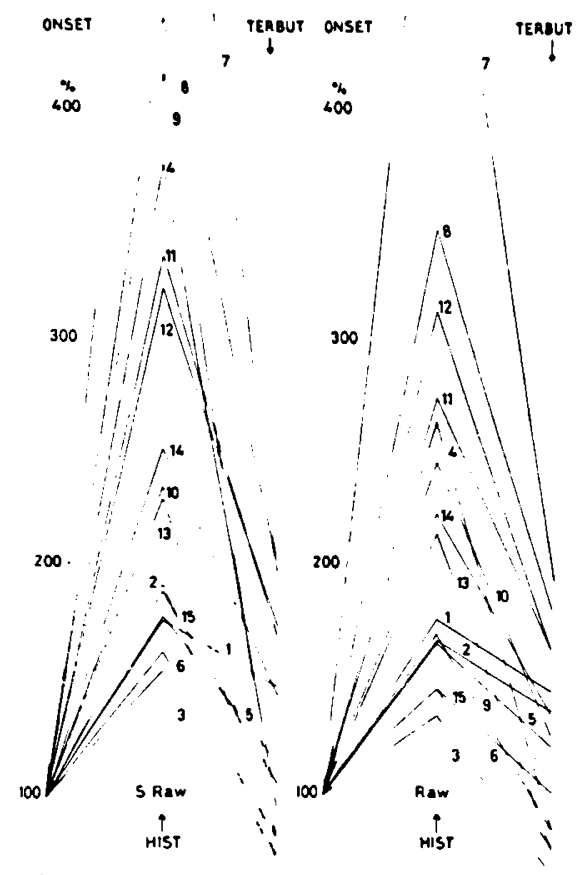

Fig. 6. Comparison of the simultaneous relative variations of SRow and Row in 15 as thmatic patients first after a histamine challenge (Hist.) and then fol-

lawed by bronchodilatation with Terbutaline (Terbut.). The values at the onset

Copyright (C) 1978 International Pediatric Research Foundation, Inc. $0031-3998 / 78 / 1208-0877502.00 / 0$

Printed in U.S.A. 